\title{
EL BILINGÜISMO COMO FACTOR CREATIVO EN «ALTAZOR»
}

Dentro de la producción literaria, tan vasta y variada, de Vicente Huidobro, se destaca un aspecto que ha llamado la atención de muchos de sus críticos: el bilinguiismo. El caso es que, en numerosas instancias, el mismo poema, ensayo o libro existe en dos lenguas: el español y el francés. La naturaleza bilinguie de la obra de Huidobro ha sido objeto de inquietud y hasta de admiración por parte de los críticos; sin embargo, permanece todavía sin estudiar. Los críticos, naturalmente, han especulado acerca de la génesis de ciertos textos - si es que éstos fueron desarrollados primero en una lengua o en otra-, pero en la mayor parte se han ignorado las posibilidades creativas que el bilingüismo ofrece ${ }^{1}$. Por tanto, en este trabajo me propongo considerar el bilinguiismo como factor creativo fundamental al sistema de expresión de Huidobro. En vez de considerar una obra como una mera traducción de su equivalente en otra lengua, cada obra deberá ser interpretada de manera tal que se considere el bilingüismo del autor como parte integrante de un sistema de expresión que hace uso específico de elementos seleccionados, ya del español, ya del francés.

- Cedomil Goić, La poesía de Vicente Huidobro (Santiago, 1974): «Temblor de cielo es el único poema en prosa de larga extensión que Huidobro publicó. Apareció en el mismo año y simultáneamente con Altazor. Al año siguiente, 1932, se publicó una traducción francesa del mismo Huidobro que nos muestra la raíz gala del título del poema: Tremblement de ciel. Es una manera de decir el equivalente celeste de «terremoto»: tremblement de terre, en francés. Así, por lo menos podemos afirmar que el título ha sido pensado en francés, pero no sabemos si ha sido originalmente escrito todo el poema en ese idioma. «El bilingüismo de Huidobro crea en ocasiones incertidumbres como ésta o bien le permite crear algunas imágenes sugerentes mediante galicismos que su creacionismo justifica sobradamente» (p. 224). Gerardo Diego, por su parte, al referirse a dicho título, lo califica como "título tan chileno" ("Poesía y creacionismo de Vicente Huidobro [1968]», en René de Costa, Vicente Huidobro y el creacionismo, Madrid, 1975, p. 215). 
Mucho se ha escrito sobre el difícil arte de traducir sin traicionar, y hoy día existe una especie de consenso en cuanto a que la poesía en general es prácticamente imposible de trasladar a otra lengua, a menos que el traductor imponga ciertos mecanismos interpretativos de su propio cuño al enfrentarse con las alternativas sintácticas, semánticas y léxicas. Edward Sapir, por ejemplo, señaló la cualidad distintiva de todo sistema lingüístico:

Every language is itself a collective art of expression. There is concealed in it a particular set of esthetic factors-phonetic, rhythmic, symbolic, morphological - which it does not completely share with any other language. These factors may either merge their potencies with those of that unknown, absolute language... or they may weave a private, technical art fabric of their own, the innate art of the language intensified or sublimated ${ }^{2}$.

Y en época más reciente, Haroldo de Campos, al exponer su teoría de la traducción, explica que:

Une fois admise comme principe la thèse de l'impossibilité de la traduction pour les textes «créateurs», ... elle engendre comme corollaire la thèse de la possibilité de la re-création de ces textes. On aura, dans une langue, une autre information esthétique, autonome, mais toutes les detx seront liées entre elles par un rapport d'isomorphisme: elles seront distinctes comme langage, mais, comme les corps isomorphes, elles seront cristallisées à l'intérieur d'une même système ${ }^{3}$.

Estas dos aseveraciones reflejan la creencia casi universal de que en poesía, en el tránsito de una lengua a otra, se obtiene un producto que debe necesariamente ser un objeto recreado. Guido Almansi, estudioso italiano de la parodia, ha llevado esta idea hasta su extremo según se refleja en un ingenioso experimento realizado en el arte de «mistranslating» ${ }^{4}$. Las distintas versiones de Huidobro en cambio no ofrecen las

${ }^{2}$ Edward Sapir, Language: An Introduction to the Study of Speech (New York, 1921), p. 420.

${ }^{3}$ Haroldo de Campos, «De la traduction comme création et comme critique», Change, 14 (febrero 1973), p. 73.

${ }^{4}$ Guido Almansi, «In Defense of Mistranslating»: «The experiment is called Imimitations to emphasize its essential mimicry: an ape aping another ape. In fact, our sacrilegious incursions on to the original text (with its astonishingly deforming results) have been accomplished not by modifying the rules of the game..., but rather by multiplying the number or operations which have been conducted since the original» (20th Century Studies, 11 [September 1974], Canterbury, Kent, p. 66). 
divergencias habituales de la traducción distorsionada. Por ello deben ser consideradas desde una perspectiva diferente y más rigurosa.

Huidobro ha escrito bastante sobre su arte poética e incluso sobre la traducción. De hecho, uno de sus ensayos más brillantes e iluminadores es «Le créationnisme», en donde define la empresa del poeta y el tipo de poesía que éste debe intentar crear:

Je vous dirai ce que j'entends par poème crée. C'est un poème dans lequel chaque partie constitutive et tout l'ensemble présente un fait nouveau, indépendant du monde externe détaché de toute réalité autre que lui-même, car il prend sa place dans le monde comme un phénomène particulier à part et different des autres phénomènes.

Le poème créationniste se compose d'images créés, de situations créés, de concepts créés; il n'épargne aucun élément de la poésie traditionnelle, seulement, ici, ces éléments sont tous inventés sans aucun souci du réel ni de la verité antérieure a l'acte de réalisation.

Si pour les poètes créationnistes ce qui est important est la présentation du fait nouveau, la poésie créationiste devient traduisible et universelle car les faits nouveaux restent les mêmes dans toutes les langues (el subrayado es mío) ${ }^{5}$.

Y más adelante encontramos esta aseveración:

Il est difficile et même impossible à traduire une poésie dans laquelle domine l'importance d'autres éléments. Vous ne pouvez pas traduire la musique de mots, les rythmes des vers qui varient d'une langue a l'autre, mais quand l'importance du poème tient avant tout à l'objet créé il ne perd dans la traduction rien de sa valeur essentielle.

L'effet reste le même, les détails de langue deviennent secondaires. La poésie créationniste acquiert des proportions internationales, elle passe a être la Poésie, et elle est accessible à tous les peuples et races comme la peinture, la musique ou la sculpture ${ }^{6}$.

Estas son en esencia algunas de las ideas básicas que informan el sistema de expresión de Huidobro. A la luz de ellas, el bilingüismo del autor, en vez de ser meramente un mecanismo de «traducción», se transforma en un elemento esencial de su quehacer poético en francés

\footnotetext{
${ }^{5}$ Vicente Huidobro, Manifestes manifestes (París, 1925), pp. 35, 37, 40.

${ }^{6}$ Vicente Huidobro, Manifestes manifestes, p. 41.
} 
y en español. Como veremos más adelante, lo que parece intentar en su obra es descubrir el isomorfismo más exacto en el proceso de lo que puede considerarse como el mismo verso o el mismo fragmento en dos lenguas diferentes. De esta manera, el poeta se permite hablar en sus ensayos y manifiestos de una lengua única para la "Poesía universal». Esta actitud con respecto al arte de la creación no es particular de Huidobro, sino que es, por el contrario, una de las características más importantes de toda la empresa vanguardista ${ }^{7}$. Sin embargo, entre los poetas innovadores de su época, es Vicente Huidobro probablemente el más singular por su experimentación tan extendida y sistemática con esta forma particular de creación y recreación literarias. En efecto, ya desde El espejo de agua (1916), muchos de cuyos poemas habrían de aparecer más tarde en Horizon carré (1917), la escritura de Huidobro parece progresar firmemente en esta vertiente bilinguie. En un estudio sobre el tema, Richard L. Admusen y René de Costa analizaron la transformación de cinco de los poemas desde El espejo de agua, hasta que eventualmente aparecieron como parte integrante de Horizon carré. Este proceso no es el de la traducción, sino más bien de dos transformas en las cuales la estructura poética ha sufrido una clara evolución en dos de sus aspectos más esenciales: la forma y la dicción. Así, El espejo de agua y Horizon carré se complementan en dos dimensiones: la temporal y la espacial. El primer conjunto de poemas sirve de sustento al segundo y le permite a la vez su expansión.

El poeta chileno escribió una considerable parte de su obra en francés: siete poemarios, numerosos ensayos, una obra de teatro y un largo poema en prosa, Temblor de cielo. Además existe un fragmento de Altazor en francés por Huidobro. El fragmento, dado a conocer últimamente por René de $\mathrm{Costa}^{8}$, es de especial relevancia para el aspecto que estamos investigando, ya que en este texto se revela la extraordinaria habilidad linguística de Huidobro en dos lenguas. Un análisis cuidadoso de dos versiones de un mismo fragmento muestra que Huidobro, en la búsqueda de un lenguaje nuevo y de una forma nueva para la poesía, hace uso de una variedad de técnicas innovadoras. Una de di-

${ }^{7}$ Como ejemplo, y en coincidencia con la afirmación de Huidobro acerca de la naturaleza del discurso poético y su traducción, Ezra Pound señala que «That part of your poetry which strikes upon the imaginative eye of the reader will lose nothing by translation into a foreign language; that which appeals to the ear can reach only those who take it in the original» (Ezra Pound, ed. by J. P. Sullivan [Baltimore, 1970], p. 44).

${ }^{8}$ René de Costa, «Reseña de Altazor, Ed. de Cedomil Goič, Revista Iberoamericana (enero-marzo 1976), pp. 141-143. 
chas técnicas podría considerarse como un collage lingüístico. Y lo denomino así porque Huidobro utiliza la yuxtaposición no sólo de imágenes, sino también de fragmentos de palabras para crear otras nuevas, las cuales están contenidas en el contexto total del canto y del poema. Lo que contribuye a que estas técnicas sean tan notables como innovadoras es el hecho de que están presentes en ambas versiones del poema. Y más aún, cada texto contiene su propio conjunto de rasgos idiosincráticos que se corresponden con aquellos del sistema linguiístico en operación:

Al horitaña de la mont zonte

La violondrina y el goloncelo

Descolgada esta mañana de la lunala

Se acerca a todo galope

Ya viene viene la golondrina

Ya viene viene la golonfina

Ya viene la golontrina

Ya viene la goloncima

Viene la golonchina

Viene la golonclima

Ya viene la golonrima

Ya viene la golonrisa

La golonniña

La golongira

La golonlira

La golonbrisa

La golonchilla

Ya viene la golondía

$Y$ la noche encoge sus uñas como el leopardo

Ya viene la golontrina

Que tiene un nido en cada uno de los dos calores

Como yo lo tengo en los cuatro horizontes

Viene la golonrisa

$Y$ las olas se levantan en la punta de los pies

Viene la golonniña

Y siente un vahído la cabeza de la montaña

Viene la golongira

$Y$ el viento se hace parábola de sílfides en orgía

Se llenan de notas los hilos telefónicos

Se duerme el ocaso con la cabeza escondida

$\mathrm{Y}$ el árbol con el pulso afiebrado

Pero el cielo prefiere el rodoñol

Su niño querido el rorreñol 
Su flor de alegría el romiñol

$\mathrm{Su}$ piel de lágrima el rofañol

Su garganta nocturna el rosolñol

El rolañol

El rosiñol

\section{FRAGMENT D'ALTAZOR}

(Madrid, 1919)

A l'horitagne de la montazon

Une hironline sur sa mandodelle

Décrochée le matin de la lunaille

Approche approche à tout galop

Déjà vient vient la mandodelle

Déjà vient vient l'hirondoline

Déjà s'approche oche oche l'hironbelle

Déjà s'approche l'hironselle

Déjà s'approche l'hironfrêle

L'hirongréle

L'hironduelle

Avec les yeux ouverts l'hirongéle

Avec ces ciseaux coupant la brume l'hironaile

L'hironciel

L'hironmiel

La belle hironréele

Et la nuit rentre ses ongles comme le léopard

Elle approche l'hirontélle

Qui a un nid dans chacune de deux chaleurs

Tel que moi je l'ai dans les quatre horizons

Déjà s'approche l'hirofrêle

Et les vagues se dressent sur la pointe de leurs pieds

Déjà s'approche l'hironbelle

Et la tête de la montagne sent un étourdissement

Elle vient l'hironruelle

Et le vent s'est fait parabole des sylphides en orgie

Se remplissent de notes les fils téléphoniques

Le couchant s'endort avec la tête cachée

Et l'arbre avec le pouls enfiévré

Mais le ciel préfère le rodognol

Son enfant gâté le rorégnol

Sa fleur de joie le romignol

Sa peau de larme le rofagnol

Sa gorge de nuit le rossolgnol

Le rolagnol 
Le rossignol

Et tout l'espace tiédit dans sa langue de tralali lilo

Tralilo lali

Avale les étoiles pour ta toilette

Toutes les petites et même l'étoilon

Trariri raro

Toutes les belles planètes que mûrissent dans le planetiers

Mais je n'achète pas d'étoiles dans la nuiterie

$\mathrm{Ni}$ de vagues nouvelles dans la mererie

Trararo riré

En el verso 1:

Al horitaña de la montazonte

que proviene de:

Al horizonte de la montaña

las dos primeras sílabas de cada sustantivo han sido ensambladas con el resto del otro sustantivo respectivamente:

$$
\begin{array}{lll}
\text { hori-zonte } \\
\text { hori-taña } & / & \text { monta-(ta)ña } \\
\text { monta-zonte }
\end{array}
$$

De manera similar en francés:

$$
\text { A l'horitagne de la montazon }
$$

que se ha obtenido de:

\section{A l'horizon de la montagne}

en cuyos versos se puede observar el mismo proceso:

$$
\begin{array}{lll}
\text { hori-zon } & / & \text { monta-(ta)gne } \\
\text { hori-tagne } & / & \text { monta-zon }
\end{array}
$$

En el segundo verso (en ambos fragmentos), este proceso se ha invertido; en este caso el segmento que se ha transpuesto es la primera mitad del sustantivo, que está indicado por un indicio, la presencia de los artículos que preceden a ambos sustantivos:

La violondrina y el goloncelo 
que proviene de:

$$
\text { La } \underset{\text { golon }}{ } \text { drina y el } \frac{}{\text { viclon }} \text { celo }
$$

y la aplicación del mismo proceso en el texto francés:

Une hironline sur sa mandodelle

proveniente de:

$$
\text { Une hiron- } \frac{}{\text { delle }} \text { sur sa mando- } \frac{}{\text { line }}
$$

En el texto francés los paralelismos fonéticos son evidentes; en algunos versos del texto español estos paralelismos están ausentes, como en el caso de los siguientes versos:

$$
\begin{aligned}
& \text { Décrochée / approche approche } \\
& \text { Déjà / déjà } \\
& \text { Déjà s'approche oche oche, etc. }
\end{aligned}
$$

\section{Descolgada / se acerca \\ Ya viene viene}

Es además importante de notar que los versos que incluyen las palabras en collage poseen una cualidad rítmica que no podría lograrse de aquellas que sirven como lexemas base. El poeta introduce con toda intención elementos nuevos en el poema con el objeto de crear nuevas realidades que no existían en la realidad y cuya existencia seria imposible fuera del contexto del poema. Estas palabras recién creadas son portadoras de significado y no deben considerarse como vacías de significación. Han sido fabricadas teniendo en cuenta elementos existentes, de alli que le sea posible al lector percibir su nueva significación. Se notará que el significado básico de los sustantivos se ha conservado, aunque el contenido semántico de cada verso no se hace evidente hasta que no se ha terminado de leer toda la iínea. La estructura morfológica que conserva la significación se ha reforzado más aún por medio del uso de los artículos el y la en las dos primeras líneas, por cuanto éstos son los artículos que dichos sustantivos exigen en la construcción que les sirvió de origen, "Al horizonte de la montaña» y «La golondrina y el violoncelo». Su función es la de mantener los marcadores originales de género y número para salvar el contenido semántico de los nuevos 
lexemas. Esta elaboración tan minuciosa indica que Huidobro no utilizó estos mecanismos tan complejos tan sólo para «destruir» el lenguaje. Al contrario, parece indicar que es posible experimentar con técnicas derivadas de las otras artes, las artes plásticas en el caso que nos ocupa. Y de más está decir que esto no es nada nuevo en la poesía cubista de Vicente Huidobro.

Otra técnica de la cual se sirve el poeta chileno y que está presente en estos dos fragmentos recuerda el uso de la escala cromática en conjunción con planos yuxtapuestos, cuyo propósito es la búsqueda de nuevos campos de experimentación. En los versos 5 al 16 en el texto francés y en los versos 5 al 18 del texto español, los mecanismos de yuxtaposición asumen cualidades y ritmos diferentes al imponerse sobre ellos ciertas transformaciones de la estructura fonológica base de los lexemas «golondrina»e «hirondelle»:

golondrina

golon. $\left\{\begin{array}{l}\text {-drina } \\ \text {-fina } \\ \text {-trina } \\ \text {-cima } \\ \text {-china } \\ \text {-clima } \\ \text {-rima } \\ \text {-risa } \\ \text {-niña } \\ \text {-gira } \\ \text {-lira } \\ \text {-brisa } \\ \text {-chilla } \\ \text {-día }\end{array}\right)$

hirondelle

hiron- $\left\{\begin{array}{l}\text {-doline } \\ \text {-bele } \\ \text {-selle } \\ \text {-frêle } \\ \text {-gréle } \\ \text {-duelle } \\ \text {-géle } \\ \text {-naile } \\ \text {-ciel } \\ \text {-miel } \\ \text {-réele } \\ \text {-télle } \\ \text {-ruelle }\end{array}\right.$

Este despliegue verbal intenta explorar las posibiliades fonológicas y morfológicas de una palabra al ser sometida a un cambio en el afijo, que es a su vez una verdadera palabra de la lengua. Conserva la estructura bisilábica del afijo español y la estructura monosilábica en francés; la calidad fonética se mantiene mediante el uso de solamente aquellos sonidos que pertenecen a la misma dimensión, o sea, líquidas y nasales en español. En francés todos los afijos contienen un sonido líquido. La calidad vocálica también se mantiene: en español mediante el uso constante de la alternancia $\mathrm{a} / \mathrm{i}$; en el texto francés $\varepsilon / \mathrm{j} \varepsilon$. Estos mecanismos se han creado con el propósito de que funcione como refuerzos del sus- 
tantivo principal, que recibe por su parte la modificación predicativa por medio de la variación de los afijos, y al mismo tiempo el poeta logra crear un ritmo parejo. La predicación del sustantivo principal, golondrina, la provee una serie de verbos: «trina», «gira», «chilla»; sustantivos: «cima», "china», etc., que son parte constituyente de una construcción comparativa elíptica: golon-[-drina como]-cima; golon-[-drina como]rima, etc. Este interesante recurso que contiene un mecanismo de predicación dentro de sí como una de sus propiedades elimina la necesidad de colocar adjetivos adyacentes $\mathbf{u}$ otros modificadores para denotar dichas cualidades.

Por último, otra técnica que quiero señalar en esta breve exposición sobre Altazor utiliza una manipulación diferente del mismo expuesto antes: la inversión del proceso de colocación de los afijos para crear palabras nuevas. En este caso, el poeta mantiene las primera y tercera sílabas de la palabra rossignol para insertar la escala musical en medio y conservar así el orden de dicha escala. Comienza con rossignol en la base, el sustantivo francés usado en ambas versiones del poema; divide la estructura silábica para producir lo siguiente:

$\begin{array}{ll}\text { ro-DO-gnol } & \text { ro-DO-ñol } \\ \text { ro-RE-gnol } & \text { ro-RE-ñol } \\ \text { ro-Ml-gnol } & \text { ro-MI-ñol } \\ \text { ro-FA-gnol } & \text { ro-FA-ñol } \\ \text { ro-SOL-gnol } & \text { ro-SOL-ñol } \\ \text { ro-LA-gnol } & \text { ro-LA-ñol } \\ \text { ro(s)-SI-gnol } & \text { ro-SI-ñol }\end{array}$

La predicación pretende ensalzar las cualidades líricas del pájaro, símbolo poético desde siempre. Muy significativo es el hecho de que se aplica el mismo principio en ambas versiones, como ya se vio con las otras técnicas, manteniéndose la misma palabra como base para conservar la predicación del valor musical. La voz española ruiseñor no pareciera adecuada para servir como tal base, ya que la variación rítmica que se obtiene es la siguiente:

rui-DO-señor

ruise-DO-ñor

Esta breve presentación de algunas de las técnicas básicas empleadas en la composición de Altazor demuestra de qué manera se pueden utili- 
zar dos sistemas lingüísticos que se relacionan y corresponden entre sí en la producción de la poesía de Vicente o «Vincent» Huidobro, cuyo paralelismo se deriva del hecho de que las relaciones inter e intralinguísticas estuvieron presentes desde su incepción.

\section{Magdalena García Pinto}

The Catholic University of America. 
